\title{
históricas sobre a calidade da lingua no galego desde o ámbito sintáctico
}

\section{Sociosyntax. Historical Approaches on Linguistic Quality in Galician from a Sintactic Perspective}

XOSÉ MANUEL SÁNCHEZ REI

Universidade da Coruña-Grupo ILIA

sanrei@udc.gal

Palabras-chave

calidade lingüística; galego; gramática; sociosintaxe.
Keywords

linguistic quality; Galician language; grammar; sociosyntax.
A preocupación pola calidade da lingua no galego é un tema que na nosa época colleu certo protagonismo no debate académico. Porén, as persoas que protagonizaron o renacer literario, político e cultural do seculo XIX e do primeiro cuartel da centuria seguinte xa notaron a importancia do emprego dunha variedade lingüística digna, limpa de españolismos desnecesarios e baseada na súa propia tradición milenaria. Un dos aspectos en que se puña o acento era a relevancia que tiña a sintaxe no medio de todas as disciplinas gramaticais para unha boa expresión en galego. Neste sentido, o obxectivo do presente traballo asenta en vermos con que prismas foi contemplada a reflexión sintáctica no marco dun modelo lingǘstico de calidade, para o cal botamos man da noción de sociosintaxe, en primeiro lugar polo contido sociolóxico ou sociolingüístico que leva implícito o tal termo e, en segundo lugar, polo contido estritamente gramatical ou sintáctico daqueles comentarios.

The concern for the quality of the language in Galician is a subject that took a certain role in the academic discussion of the present epoch. However, the people who starred in the literary, political and cultural revival of the nineteenth century and the early years of the following century already noticed the importance of the use of a linguistic variety worthy, clean of unnecessary españolismos and based in its own millenary tradition. Among all the grammatical disciplines, one of the most notable aspects was the relevance of syntax for a good expression in the Galician language. In this regard, the objective of this work is to see how syntax was contemplated in the framework of a quality linguistic model. To do this, we use the word Sociosyntax, first of all, by the sociological or sociolinguistic content that implies; and, secondly, by the strictly grammatical content of comments made in the Rexurdimento and in the early years of the twentieth century. 


\section{XOSÉ MANUEL SÁNCHEZ REI}

\section{Introdución}

\subsection{Sintaxe e calidade da lingua}

Nos últimos tempos, cobrou corpo en ámbitos académicos da Galiza o debate á volta da calidade lingüística, nomeadamente cando o idioma é utilizado na esfera pública. Segundo algunhas opinións, o facto de a lingua aparecer hibridizada en varios planos e en diferentes niveis co español (isto, é, no campo fonético, morfolóxico, lexical, textual e mesmo sintáctico) pode entenderse como algo positivo, pois non sería senón máis un exemplo da expresividade de que dispón a comunidade de falantes para se exprimir en galego. Falaríase, en tal suposto, dun "recurso comunicativo", conforme defende Iglesias Álvarez (2013: 187), ou dunha ferramenta para se adaptar ás exixencias de determinados contextos comunicacionais, segundo a opinión de Gugenberger (2013: 30).

Para outras persoas, en confronto, o proceso de normalización do idioma, tendo en conta a situción de contacto entre as dúas linguas e a erosión que a española provoca na galega, debe correr necesariamente paralelo a un uso da lingua liberado, na medida do posíbel, de influencias alleas e propositadamente próximo da tradición histórica galego-portuguesa no referente ás súas características gramaticais, vocabulares etc. En harmonía con tal suposto, dificilmente se poderá avanzar na recuperación da lingua se non se proxectar socialmente unha variedade lingüística digna destonada de castelanismos gratuítos, capaz de marcar fronteiras nítidas co español e de ser vista polo conxunto de falantes como unha verdadeira lingua en vez de como unha variedade profundametnte interferida. De acordo con estas impresións ${ }^{1}$, nos tempos actuais tamén non parece ser suficiente conformarse unicamente coa militanza consciente no idioma, sobre todo no caso de quen tiver responsabilidades na súa promoción social, investigación científica, docencia académica e defesa política, pois faise precisa unha certa vontade de emprego que parta duns mínimos principios de calidade 2 .

$\mathrm{Na}$ verdade, en congruencia co que sinalamos noutro traballo (Sánchez Rei, 2014b), a vontade de dignificación do galego mediante un uso modelar responde a unha ansia que remonta as súas primeiras manifestacións á segunda metade do século XIX e que se mantén con firmeza no primeiro cuartel da centuria seguinte, nun tempo caracterizado socioliterariamente como "diferencialista" ou "enxebrista" (Fernández Salgado; Monteagudo Romero, 1995: 133-140). Nese período, xa reinstaurado o uso literario da lingua, unha parte de autores e autoras reparou na necesidade de empregar na literatura un galego que fose, a seu ver, o máis autóctone posíbel, nalgúns casos mesmo a forzar as propias características do idioma incorrendo nos pseudogaleguismos, de practicamente emprego exclusivo na escrita. As consideracións daqueles eruditos apareceron en traballos de moito variada índole, pois foron

\footnotetext{
${ }^{1}$ Sobre este particular, poden verse, entre outros, os traballos de Sanmartín Rei (2008), Freixeiro Mato (2009; 2014), Sánchez Rei (2014a) etc., en que se fai fincapé desde diferentes prismas na necesidade dunha referencia modelar para o uso do galego.

${ }^{2}$ Como se torna obvio, ese modelo de lingua non tenciona eliminar todas as variedades dialectais, idiolectais, locais ou populares, en que o galego é tan rico, mais aspira a ter unha referencia modelar no dominio público, asentada en si propia, cunhas barreiras claras a respecto das influencias que recibe como produto do contacto co español e que tanto danan as súas estruturas gramaticais e os seus recursos vocabulares. E tamén non pretende cuestionar o meritorio labor na manutención do idioma de centos de xeracións precedentes nin a non menos meritoria decisión de optar polo galego como medio de expresión único ou preferencial no caso de neofalantes, pois achamos que na conxunción de utentes tradicionais con nefolantes asenta o futuro do galego.
} 
dadas a lume en obras de carácter gramatical ou lexicográfico, en xéneros paratextuais ${ }^{3}$, en publicacións periódicas etc., e nin todas posúen, dun punto de vista actual, a mesma validade e rigorosidade, embora cada unha sexa expoñente da vontade de dignificación do idioma co emprego duns trazos gramaticais ou vocabulares premeditados. Todo ese pensar, en definitivo, ilustra con facilidade a preocupación que suscitaban tales asuntos entre os protagonistas do Rexurdimento oitocentista ou na época das Irmandades da Fala e do Grupo Nós.

Na procura desa presumíbel variedade lingüística máis auténtica, diversas cuestións foron orientando o debate. A este respecto, as reflexións sobre a lingua galega abranxen nese período unha notabilísima cantidade de documentación que non pretendemos analizar aquí. Algunhas desas impresións decantáronse por asuntos máis centrados en aspectos gramaticais, tales como a necesidade duns bos estudos de gramática, recollendo así a tantas veces citada idea de Rosalía de Castro cando denunciaba en 1863 que tivo de escribir Cantares gallegos sen "gramática nin regras de ningunha clás" (CG 11), para alén da lingua oral popular de que ela era unha experta coñecedora. De facto, a primeira obra que merece ser chamada Gramática no discurso filolóxico galego corresponde á de Saco Arce (1868) e, debido ás circunstancias en que aparece e ao contexto sociocultural e político da altura, non contou nin coa socialización necesaria nin foi coñecida para alén de cenáculos eruditos (Sánchez Rei, 2005).

Varias daquelas opinións desenvolveron aspectos directa ou indirectamente vinculados á sintaxe e son precisamente esas ideas as que máis interesan para os nosos obxectivos. Como afirma García-Miguel (2000: 200) nun estudo sobre tipoloxía lingüística, todas as linguas "teñen sintaxe: relacións de dependencia, constituíntes (frases e cláusulas), funcións sintácticas, unidades complexas, etc.", mais diferéncianse "nos esquemas formais utilizados nas súas construccións e, sobre todo, nas técnicas utilizadas para expresar relacións sintácticas”. E son precisamente eses esquemas e trazos idiosincráticos os que, para o caso do galego, centrarán na altura unha notábel parte do debate público á volta da súa promoción, nunhas ocasións de forma a representaren albos dunha pretensa sublimación e noutras para seren modelos en que denunciar a influencia do español.

Ao paso, polo estado dos estudos lingüísticos e filolóxicos sobre o galego na altura, non poucas das consideracións que suscitou a compoñente sintáctica fan que os comentarios se centren no que aparece denominado como construcións, fraseoloxías, expresións, locucións, réxime ou xiros, que se poden entender, embora vagamante, como referencias encaixábeis no amplo abano da reflexión sintáctica. En tales circunstancias é que se pode entender a seguinte

\footnotetext{
3 A falar dos prólogos, Sanmartín Rei (2002a: 166) refire as palabras seguintes, facilmente extrapolábeis a outras tipoloxías de documentación: "as reflexións lingüísticas forman parte cosubstancial dos paratextos, na procura da formación dunha opinión sobre o emprego do idioma, e, sobre todo, cunha vontade correctora das desviacións. A reconsideración da utilización de determinadas formas aparece en boca duns autores que acaban por se converter en filólogos, como sucede habitualmente en situacións de anormalidade lingüística, cunha falta de separación de planos de intervención entre escritores e gramáticos". E acrecenta: "Isto, visto actualmente como unha eiva, non deixa de ser unha necesidade imposíbel de obviar: os escritores dunha lingua 'minorizada' que non conta co apoio dos poderes públicos son realmente os seus gramáticos, pois coa súa práctica están dotando a nosa lingua dunha determinada fasquía, poucas veces con falta de premeditación, reflexión e discusión". Moitas desas impresións son as que se recollen nalgunhas seleccións de textos de contido (socio)lingüístico, cal RLG ou PTG, que serán utilizadas aquí para os nosos propósitos.
} 
opinión de Manuel García Blanco ${ }^{4}$, tirada das súas interesantes Consideraciones sobre la decadencia y rehabilitación de la lengua gallega de 1912; nese traballo, o autor, achegando unhas interesantes reflexións de carácter sociolingüístico, facía fincapé nesa perda de autenticidade idiomática:

hay quien tolera que se hable el gallego en determinadas circunstancias, mas solo a condición de que sea un gallego modernista, sui géneris, limpio de sus voces más enxebres y características, de sus giros y modismos más peculiares, más típicos ${ }^{5}$. (CDR 10)

\subsection{Sintaxe e codificación}

Mais moitos daqueles textos que salientaban a necesidade da utilización dun galego máis auténtico poden ser situados a medio camiño entre a sociolingüística e a gramática, a partillar esferas con ambas estas disciplinas lingüísticas. Para as nosas finalidades, o termo sociosintaxe parece capaz de maridar esa vontade social de aprimorar o uso da lingua, cando menos na escrita, coa compoñente sintáctica, que é, en resumo, a columna vertebral dun idioma, segundo indicamos noutro lugar (Sánchez Rei, 2019: 119). Obviamente, non é a primeira ocasión en que se comenta ou en que se aborda a sintaxe desde a teorización sociolingüística. Tivemos aquí en conta, por exemplo, as impresións do clásico traballo de Hudson (1981: 55-58), cando, a falar das variedades lingüísticas e dos rexistros, entende que a morfoloxía, a sintaxe e o léxico dan a entender estado social e grao de educación dos invididuos. E continuando nesta liña, a sintaxe, para este autor, correspondería á marca de cohesión social ao facer que cada falante tentase eliminar do seu propio idiolecto alternativas de construción para así confluír coas detectábeis dentro da gramática, coas mellor consideradas socialmente ou coas coincidentes con outros grupos de falantes de maior prestixio e proxección social.

Así pois, a vontade de empregar unha lingua de calidade, en que a sintaxe sexa un fundamental albo de referencia, fai que esa ansia presente terreos comúns coa sociolingüística e coa reflexión gramatical. Decidirmos como se podería caracterizar cada unha desas seccións é o que se tenta sintetizar esquematicamente do modo seguinte:

\footnotetext{
${ }^{4}$ Sobre a figura de Manuel García Blanco e sobre a súa obra Consideraciones sobre la decadencia y rehabilitación de la lengua gallega é de consulta obrigada o volume coordinado por Sanmartín Rei (2012).

${ }^{5} \mathrm{O}$ destaque da tipografía grosa é noso en todos os exemplos deste traballo.
} 


\begin{tabular}{|c|c|}
\hline \multicolumn{2}{|c|}{ SOCIOSINTAXE } \\
\hline $\begin{array}{l}\text { Aspectos de teor } \\
\text { sociolingüístico }\end{array}$ & Aspectos de teor sintáctico \\
\hline $\begin{array}{l}\text { Reflexións públicas sobre aspectos } \\
\text { gramaticais, nomeadamente } \\
\text { sintácticos e fraseolóxicos }\end{array}$ & \multirow{6}{*}{$\begin{array}{l}\text { Recomendacións sobre o uso de } \\
\text { determinadas construcións sintácticas, máis } \\
\text { acordes, en xeral, coa tradición lingüística } \\
\text { galego-portuguesa }\end{array}$} \\
\hline $\begin{array}{l}\text { Percepción da necesidade } \\
\text { dunha referencia modelar }\end{array}$ & \\
\hline $\begin{array}{l}\text { Encaixamento actual no ámbito da } \\
\text { planificación lingüística } \\
\text { e codificación do corpus }\end{array}$ & \\
\hline $\begin{array}{l}\text { Vontade de proxección social, cando } \\
\text { menos diafásica e contextualmente }\end{array}$ & \\
\hline $\begin{array}{l}\text { Vontade de mellora do uso social do } \\
\text { idioma e } \\
\text { da súa dignificación para o dotar de } \\
\text { prestixio }\end{array}$ & \\
\hline $\begin{array}{l}\text { Inclusión e aproveitamento estilístico } \\
\text { situacional doutras variedades do sistema } \\
\text { lingüístico galego-portugués }\end{array}$ & \\
\hline
\end{tabular}

\section{Cadro I}

Trazos xerais da sociosintaxe

Nesta liña, a ampliarmos a vision de Hudson para o caso galego, no sentido de escoller diversas hipóteses entre alternativas de construción, a sociosintaxe tería como obxectivo xeral mellorar a utilización da lingua, para o cal parece necesaria unha estratexia de referencia ou uns pasos que se deben seguir. Así, dun punto de vista actual centrado na calidade lingüística e a pensarmos en como se pode combinar a compoñente sintáctica coa vontade de construción dun modelo de lingua culto, obteriamos os degraos seguintes:

\section{(1) Selección}

Na sintaxe, como sinala Martins (2000: 129), quen fala ou quen escribe ten a posibilidade de se decantar por diferentes tipos de frases, cláusulas etc., obedecendo a un número máis ou menos restrito de regras ríxidas e é así capaz de producir, en número infinito, construcións novas e intelixíbeis. Hai que deixar notar que a propia sintaxe favorece a existencia de diversas hipóteses de selección por parte do conxunto de utentes dun idioma. Pensando en termos fonolóxicos, por exemplo, non se pode acrecentar nin diminuír o número de fonemas nin, acudindo aos dominios da morfoloxía, tampouco seremos capaces de mudarmos a cifra das unidades morfemáticas flexionais do verbo. Mais en sintaxe isto non acontece e non hai un número determinado nin de frases, nin de cláusulas, nin de enunciados. Nestes medios, a vontade de selección fica formulada no sentido en que o uso de estruturas sintácticas máis xenuínas merece ser preferencial antes que as claramente erosionadas polo español ou aquelas que foren máis utilizadas hoxe en día por coincidiren coas desta lingua. Nas salas de ensino, cando preguntamos ao estudantado pola frecuencia de uso de determinadas construcións sintácticas, costuma responder, excepto en contados casos, que as que máis utiliza son as máis 


\section{XOSÉ MANUEL SÁNCHEZ REI}

próximas do castelán ou as idénticas con esta lingua, deixando polo camiño alternativas tan galegas como as anteriores, embora diferenciais do punto de vista da estruturación gramatical.

Por iso, ao falarmos de selección, estamos a nos referir a mostras como as primeiras dos seguintes pares de exemplos: a noso ver merecen ser escollidas pola súa autoctonía antes que as segundas posibilidades, as cales, nalgúns casos, sempre poden ficar como variantes estilísticas ou expresivas e así seren úteis ferramentas para unha mellor axilidade textual. Véñennos á mente, poñamos por caso, a preferencia de determinadas construcións clausais amodotemporais con infinitivo flexionado (Cómpre saírdes con tempo vs. Compre que saiades con tempo), a utilización preferente do acusativo cando for suxeito dun infinitivo (Infórmoo de que xa ten aqui os impresos vs. Infórmolle de que xa ten aqui os impresos), o uso de certas partículas invariábeis (conxuncións e MD: mais vs. pero; no entanto / porén / con todo vs. así a todo) etc.

(2) Supresión e/ou secundarización

Máis outra subsecuente actuación no marco dunha sintaxe con vontade dignificadora para a lingua pasa necesariamente pola progresiva eliminación de posibilidades claramente influencidas polo español. Nuns casos non formula dúbidas darmos prioridade exclusiva a determinadas estruturas, en canto noutros a prudencia leva a sermos cautelosos e a optarmos por unha clara secundarización. Podemos citar, a modo de exemplos, as rexencias verbais estrañas ou o uso inadecuado da marca de caso co CD (Vin o teu amigo vs. *Vin ao teu amigo; etc.), a colocación dos clíticos diverxente coa tradición lingüística galego-portuguesa (Resumiume o partido vs. * Me resumiu o partido; Veño para te ver vs. Veño para verte; etc.), as estruturas frásicas de dubidosa orixe no ámbito nominal (Queren máis un? vs. ?Queren un máis?; Tes o libro diante de ti vs. *Tes o libro diante túa; etc.), as construcións pronominais de reflexividade e reciprocidade indirectas (Lavou os pés vs. *Lavouse os pés vs. Lavouse; As dúas amigas bicáronse vs. ? As dúas amigas déronse un bico; etc.), determinados tipos de concordancia frásica e clausal (Ofrecinlle un café a el / Ofrecinllo vs. Ofrecinlle un café ao teu amigo; Chegou un grupo de amigos vs. Chegaron un grupo de amigos; Bebeu un pouco de anga / Bebeu unha pouca anga vs. *Bebeu unha pouca de anga vs.; etc.), a correcta utilización do FS nos casos en que for de regra (Avísame cando chegares vs. * Avisame cando chegues), o uso do IF nos contextos en que for obrigatorio (De eles o saberen, terían con certeza outro comportamento vs. ${ }^{*} D$ e eles o saber, terían con certeza outro comportamento), a necesaria ausencia do artigo en cláusulas do relativo que introducidas por preposición ( $A$ casa en que moraba é pequena vs. * A casa na que moraba é pequena) etc.

\section{(3) Valorización}

Finalmente, sen renunciarmos aos anteriores dous elementos, unha lingua de calidade coa sintaxe como eixo vese igualmente perpasada pola necesaria ponderación das variedades coloquiais, dialectais e populares, e do seu potencial expresivo. O galego, debido aos estratos sociais que o deron conservado co andar dos séculos e aos contextos en que foi usado, tamén posúe no dominio sintáctico unha ricaz diversidade que, aproveitada coas cautelas necesarias, é capaz de servir para aprofundar na tradición lingüística galego-portuguesa e para se aproximar conscientemente dela, marcando, en ocasións, nítidas barreiras face a outras linguas próximas.

Un caso que se podería citar ao respecto sería o das estruturas con interpolación pronominal (Xa cho ela dixo moitas veces vs. Xa cho dixo ela moitas veces), que hoxe son comunmente adscritas ás falas de xente idosa e a idiolectos arcaizantes e que se detectan de preferencia nas variedades orais, populares e rurais de galego (Sánchez Rei, 2014b); achámonos neste caso cun trazo morfosintáctico que, usado sen facer unha utilización abusiva, constitúe non unicamente 
un claro elemento diferenciador dunha praxe lingüística de calidade, mais tamén unha rendíbel marca de estilo, moito na liña do comentado por algunhas gramáticas contemporáneas (Sánchez Rei, 2014b: 125). Máis un exemplo vén dado pola observación da mudanza dos cadros actanciais de certos predicados verbais e polas, en ocasións, notorias e subsecuentes alteracións de significado, expoñentes dunha rendibilísima recursividade sintáctica e semántica (Cando o vin, batía dous ovos para a torta / Cando o vin, batía en dous ovos para a torta / Camiñando polo monte, bateu cun petróglifo nunca documentado / O seu pai era violento e batialles con frecuencia etc.).

\subsection{O noso punto de partida}

A visión que pretendemos achegar neste traballo é histórica e por iso os tres principios que acabamos de formular non aparecen nos textos que manexamos de maneira explícita. Isto non impide, porén, que varias desas documentacións con que traballamos non recollan impresións que inciden nos tres criterios expostos. Ao mesmo tempo, non hai que esquecer que a época en que foron publicados os textos corresponde a un longo período de tempo e que os coñecementos e publicacións sobre a lingua galega foron felizmente acrecentándose: desde o Rexurdimento oitocentista até ao comezo da Guerra Civil, median máis de setenta anos e, nese tempo, o avanzo epistemolóxico foi significativo, segundo Sanmartín Rei (2002a: 178), mudanza da cal eran conscientes os últimos protagonistas de todo ese proceso. Así, gramáticos como Cuveiro Piñol, Saco Arce, Valladares, Lugrís Freire ou Couceiro Freijomil, entre outros, coadxuvaron poderosamente en todo este proceso de coñecemento da estrutura gramatical do galego e sentaron as bases do notabilísimo desenvolvemento da literatura especializada con que a lingua conta na actualidade.

\section{Sociosintaxe e modelo lingüístico de calidade: exemplos históricos}

\subsection{A sintaxe, núcleo da lingua}

Imos expor a seguir algunhas ideas xerais que inspirou a compoñente sintáctica e que, conforme deixamos dito máis acima, nalgúns casos poden asimiliarse con relativa facilidade aos principios de selección, supresión/secundarización e valorización formulados. Mais, antes de entrarmos neses pormenores, talvez non sobre aquí sinalarmos como a sintaxe foi alzada como bandeira para a entender cal a cerna íntima do idioma, nunha liña parecida á asunción daquela como a columna vetebral do idioma. Certo é que a cuestión da autoctonía léxical como elemento capaz de dotar a expresión literaria dunha maior galeguidade foi un tema recorrente entre os eruditos da época. No entanto, algunha xente tamén xulgaba que o que distinguía un estilo caracterizado pola súa autenticidade idiomática non viña dado soamente pola utilización de vocabulario galego considerado "enxebre", mais tamén pola potenciación da sintaxe identificada como máis auténtica. Deste modo, en 1887, Aureliano J. Pereira, nun artigo intitulado "Academia gallega”, afirmaba nas páxinas de Galicia. Revista Regional que unha boa escrita non respondía só á utilización de léxico galaico, mais debía igualmente caracterizarse pola estrutura e polos trazos sintácticos:

En cuanto á los giros y frases, mucho tendríamos que decir, mas no es nuestro propósito tratar extensamente este punto. Pero séanos permitido consignar que para escribir en gallego, no basta emplear palabras gallegas; es preciso conservar la esencia, lo que es verdaderamente gallego; la estructura, la sintáxis, el giro, la propia forma literaria de nuestro idioma. De otro modo sucede, y esto lo vemos con mucha frecuencia, que las poesías 


\section{XOSÉ MANUEL SÁNCHEZ REI}

que se titulan gallegas, son, ó parecen, poesías castellanas traducidas al gallego [...]. Y si esto sucede en el empleo de vocablos y en la parte ortográfica, ya puede presumirse lo que acontecerá con los giros y frases, cuyo conocimento no es tan fácil. (RLG, 277)

\subsection{Sintaxe e gramática}

Outro asunto que debemos salientar é que, para alén de se entender como o núcleo dunha lingua, o concepto de sintaxe foi asimilado case sinonimicamente ao concepto de gramática, en congruencia con algúns marcos teóricos actuais (Riemsdijk; Williams, 1990: 23; García-Miguel; Cabeza, 2000: 546; etc.). Así, en determinados textos, ambos estes nomes parecen ser empregados case como equivalentes; nun artigo de Johan Vicente Viqueira dado a lume nas páxinas d'A Nosa Terra e intitulado "Da renascenza lingǘstica", reivindicábase unha lingua modernizada que había que crear partindo do vocabulario, da súa pronuncia e dos seus trazos gramaticais, entre os cales, descartando a compoñente lexical e a fonética, parece ter fácil encaixamento a sintáctica:

Pra os tempos novos fala nova! O galego é algo que se fai, que se crea non algo feito. Mas, pra facel-o hai que coñecer as suas posibilidades actuaes (a sua gramática) e as suas posibilidades futuras en germ n'as actuaes [...]. Mui ben di meu amigo Correa Calderón: temos que crear o galego do noso século! -Eu engado: o galego integralmente, no seu léxico, na sua gramática, na sua pronuncia. (ANT, 77: 4-5, 06.01.1919)

A identificación entre sintaxe e gramática é outra das impresións que igualmente parece deducirse dun texto de Uxío Carré, intitulado “Apropósitos, varios años y pueblos” e datado en 1913, en que, para alén desa idea, defende un modelo lingǘstico digno e critica que para conseguir o riso fácil e efémero de determinados subxéneros dramáticos, como os apropósitos, non se precisa de barbarizar desnecesariamente a lingua:

En todos [os apropósitos], o al menos en casi todos, figuran personajes hablando en gallego, pero desgraciadamente los autores emplean un gallego desfigurado, bárbaro, y lleno de disparates con objeto de provocar la risa del público indocto, como si no pudiera conseguirse por otros medios. Mas ya se ve, el ingenio es más difícil de encontrarse que los chistes vulgares y que los retruécanos del mal gusto; y retorciendo la gramática y el sentido común están al alcance de todas las inteligencias, aún las más mediocres. (MCB, 92)

Outrosí, entre as relacións da sintaxe coas diferentes disciplinas lingüísticas, para alén das presentemente consabidas coa morfoloxía (morfosintaxe), co léxico (sintaxe lexical), co texto (sintaxe supraoracional) etc., están as que se poden sinalar coa compoñente fónica, o que se estuda co nome de "fonética sintáctica" ou "fonética combinatoria". Eses puntos en común entre ambos os saberes chamaron a atención de certos autores de finais do século XIX e dos primordios do seguinte, sobre todo ao observaren como a fala popular era un firme expoñente de tales fenomenoloxía representativas da fonética sintáctica e como estas debían plasmarse na lingua escrita. Neste sentido, merecen ser salientadas as seguintes impresións de Antonio

\footnotetext{
6 Para unha descrición deste dominio común partillado pola sintaxe e pola fonética no caso da lingua galega, véxase Freixeiro Mato (2006: 191-216), cando afirma que o campo de análise dela "estuda as modificacións fonéticas que sofren as palabras por influencia doutras con que están en contacto na frase" (2006: 193).
} 
López Ferreiro no seu prefacio "Un aviso ao bondoso lector" d'A Tecedeira de Bonaval, obra saída do prelo en 1895 :

De tal modo conserva a nosa faliña a vertú qu'os filólogos chaman aglutinante, que moitas diciós para poder millor, como si dixéramos, encolarse cas que lle siguen, ou cas que van rixidas delas, perden ou cambéan a letra ou letras derradeiras. Nótase esto especialmente nas perposicions en e con; a pirmeira, para quedar mais solta e libre para xuntarse co artícolo que dela vay rixido, íspese da e do principio; e a segunda, pra o mesmo fin, despréndese da $o$ e da $n$. Asemesmo, a $r$ con que rematan os infinitivos, cambéase en $l$, que é consonante líqueda mais mol, cando ten que axuntarse cos pronombres personales de terceira persona; e a $s$ final dos pronombres de plural da primeira persona, cambéase tamén en $l$, cando detrás do pronombre vay enseguida o artícolo correspondente; por enxemplo: nol-os gallegos por nos os gallegos. (PTG, 122-123)

Noutros textos da altura, algún autor manifestou as singularidades gramaticais e fonéticas do galego facendo fincapé, xustamente, en que tales particularidades son exclusivas e que mesmo non se achan noutras linguas nin variedades hispánicas nin até no portugués. Tal é o que se pode ler nun fragmento da conferencia proferida por Manuel Lugrís Freire, intitulada "Unha lección de etnografía" e organizada pola "Seición de Cultura" da Irmandade da Fala da Coruña, que sería despois parcialmente publicada nas páxinas d'A Nosa Terra; nela, o polígrafo mariñán, na súa liña de identificar como idiomas diferentes o galego e o portugués, tan contraria ás ideas de Viqueira e aínda á doutros intelectuais da altura, observaba a idiosincrasia dos trazos propios da lingua contrapóndoos mesmo á variedade lusitana:

A lingua de Galicia, a que acadou mais axiña cultura literaria entre os idioma hispánicos, tên características propias, vernáculas, que fan d'ela un instrumento orixinal. Aparte do seu réxime e construción, das particularidades da súa morfoloxía, e do número de sons que rexistra a sua fonética, a música, o "modus vivendi" é de tal natureza que rompe a semellanza con toda-as demais, incruso co portugués. (ANT, 182: 2, 01.04.1923)

\subsection{A necesidade de estudos sintácticos}

Outrosí, a necesidade de estudar rigorosamente a lingua galega foi unha demanda que se rexistra con relativa frecuencia nos textos de finais do século XIX e dos inicios da centuria seguinte. Non é de estrañar, nestes medios, que se denunciase o estadio da investigación en sintaxe, facéndose notar a súa total secundarización, o que se torna facilmente explicábel a termos en conta algúns factores: en primeiro lugar, como algo idiosincrático da tradición gramatical galega, temos de nos referir ás circunstancias sociais e históricas en que aparece, entre as cales cómpre ponderarmos o seu aparecemento serodio a respecto doutras linguas próximas (Sánchez Rei, 2005); e en segundo lugar, a maior parte das gramáticas do mundo occidental caracterizouse antes polo seu morfocentrismo que pola súa dedicación á sintaxe (Cidrás Escáneo, 2005: 339; Neves, 2001: 49-60; ou o clásico traballo de Volóshinov, 2014: 184-185), que ficou, a pesar da súa importancia, como a grande esquecida na reflexión gramatical até á segunda metade do século XX. Ambos os condicionantes incidiron en que a investigación sintáctica non contase no discurso gramatical galego con equivalentes cotas de dedicación que outras disciplinas lingüísticas. 
Así as cousas, non vira estraño que se salientase esa necesidade e tamén que a sintaxe non debía ser asimilada á do español nin que as variedades locais tiñan de ser "superficialmente" preferidas. Tales ideas aparecen nun escrito anónimo intitulado "Filología gallega", editado n' $A$ Nosa Terra dirixida por Leandro Carré Alvarellos nos primordios do século XX; o texto, en que se tamén exhortaba os galegos e as galegas a estudaren a súa propia lingua, puña o acento precisamente nesas cuestións, ben como no indispensábel que era a análise da fonética, do vocabulario e, aliás, da sintaxe do galego, pois había escritores/as que non posuía nos coñecementos necesarios:

Es ya tiempo de que al estudio de la lengua gallega se dedique por los hijos del país, cuya ignorancia contrasta con el conocimiento que de aquélla tienen los extranjeros, toda la atención que se merece [...]. Para poder tratar acerca del idioma gallego se hace preciso estudiarlo, pero no superficialmente y en una sola comarca y aplicándole, como generalmente se hace, las reglas de la gramática castellana, error en que incurren muchos. Es indispensable compenetrarse bien de la fónica, léxico y sintáxis gallegos. (ANT', 11.08.1907, 4)

Máis un exemplo da preocupación polo emprego dos trazos sintácticos tradicionais do idioma é o que temos na seguinte mostra de Johan Vicente Viqueira. O autor, na conferencia "Nosos problemas educativos", proferida na Irmandade da Fala da Coruña e que máis tarde sería publicada en varios números d'A Nosa Terra durante o ano 1918, ponderaba, xunto a outros temas, a relevancia de esta compoñente gramatical ser debidamente observada: "Precisamos do mesmo geito estudos de sintaxis, sobre a maneira peculiar de formarmos as frases, que vai tan perdida" (ANT, 62: 4, 30.07.1918).

E, como se torna lóxico imaxinarmos, a pregunta de que persoas ou organismos debían levar a cabo eses estudos inspirou algúns comentarios. Así as cousas, entre os debates que se deron en finais do século XIX e que callaron na fundación da Real Academia Galega en 1906 estaban os labores que a tal institución tiña de desenvolver. Nun artigo de Aurelio Elías Martínez aparecido en El Heraldo Gallego durante os meses de maio e xuño de 1879 e intitulado precisamente "Academia Gallega", o autor sinalaba algúns dos problemas da literatura galega oitocentista (polimorfismo, presenza de españolismos e de formas marcadamente populares, uso e abuso de diminutivos etc.), ao paso que encomendaba ao futuro organismo o traballo de velar pola utilización dunha lingua libre de léxico e xiros alleos:

Por eso resulta tan desigual la poesía gallega, y no es extraño, porque cada escritor adapta á su modo los vocablos y jiros [sic] que cree más propios y castizos [...]. Los trabajos que emprendería la Academia Gallega serían de incalculable trascendencia para nuestra literatura regional. La confección de un Diccionario completo: publicación de una Revista, escrita en gallego, en donde se debatiesen con la amplitud necesaria, todas las cuestiones mas intimamente relacionadas con nuestro idioma, procurando desterrar toda incorrección, todo giro que no sea genuino y propio de nuestra lengua, y todo vocablo que hallándose en uso no sea de legítima procedencia gallega. (RLG, 196-197)

\subsection{Sintaxe e hibridación lingüística}

Como quer que sexa, a existencia de estudos sobre sintaxe galega podería coadxuvar en que os diferentes tipos de mestura sintáctica co español fosen identificados de modo máis sinxelo e, consecuentemente, evitados. Perante esa ausencia de literatura especializada, algunhas 
reflexións fixeron fincapé, central ou secundariamente, na mestura (morfo)sintáctica co español. Xa no século XIX, o polígrafo José Pérez Ballesteros denunciaba que varios dos cantares tradicionais que compilou nos tres volumes do seu Cancionero popular gallego, publicado en 1885-1886, daban mostras de léxico e de construcións foráneas, facendo notar que até os rexistros máis populares e coloquiais da lingua non tiñan de ser receptores gratuítos de tales influencias (Sánchez Rei, 2014b: 111-117). Mais, obviamente, non foi nin sería o único que puña o acento nesas cuestións. O seguinte caso, asinado coas siglas L. C. (presumibelmente Leandro Carré Alvarellos) e dado a lume n'A Nosa Terra co título "Conversas filolóxicas", facía unha chamada de atención sobre colocacións erradas do pronome átono, un dos trazos que mellor serve para evidenciar unha asimilación deficiente da sintaxe galega; lembremos aquí que xa Lugrís Freire (1931: 87) sinalaba naquela época que a correcta disposición das formas pronominais clíticas é o que daba máis enxebreza ao galego e, con efecto, posibelmente tivese unha opinión similar á de L. C. perante cláusulas introducidas por un pronome persoal clítico:

Non atopo ben a ortografía empregada no folleto que se me cita (non digo o título porque non vexo a necesidad). Deixo a un lado as formas "Che habían", Che dijo", etc., que son castelanismos xa que en galego dise "tíñanlle" (emprégase adoito o verbo ter e non haber) e "díxolle". (ANT, 211: 2, 01.04.1925)

As mesmas siglas de L. C. voltan a asinar un outro comentario agora intitulado "Conversas filolóxicas $\hat{o}$ ao o" e aparecido tamén no mesmo decenario para dar conta dos encontros da preposición $a$ co artigo $o$ e subsecuentemente tratar de proscribir a presenza desa partícula relacional acompañando o $\mathrm{CD}$, un dos aspectos en que máis se deixa(ba) notar a influencia da sintaxe española no galego e que foi identificado polo autor como "unha falla"7:

No galego, coma no portugués, que ten tanta semellanza, débese escribir: vai ao muiño, (caso de dativo) mais non debe de se dicir endexamais vin ao muiñeiro, senón o muiñeiro, (caso de acusativo). Como se ouservará no primeiro caso úsase a contraición de preposición e artículo, mais no segundo sômente emprégase o artículo [...]. Para que se vexa mellor esta diferencia de ao ou o según os casos, poñerei un exempro comparativo con frases en galego, portugués, castelán, e tamén e francés, para aqueles que ten mais importancia o que se fai en países estranxeiros; porque en francés ocurre o mesmo que no galego:

Fui al campo y vi al herrero

Fun ao campo e vin $o$ ferreiro

Fui ao campo e vi o ferreiro

Je suis allé au champ e j'ai vu le forgeron $[\ldots]$

O dativo indica na oración a persoa ou cousa á quen afecta a sinificación do verbo, sen ser ouxeto direito d'ela. Pódese facer ésta pregunta ¿para onde? ¿para quen? [...]. O acusativo indica o termo direito da acción do verbo transitivo, é dicir, do verbo cuia acción pasa á outra

\footnotetext{
${ }^{7}$ Na realidade, o encontro da preposición a co artigo o e o modo de o representar xa protagonizara algúns debates no século XIX (cf. Freixeiro Mato; Sánchez Rei; Sanmartín Rei, 2005: 184-186) e trouxera consigo varias hipóteses ortográficas, algunhas certamenente minoritarias e outras máis

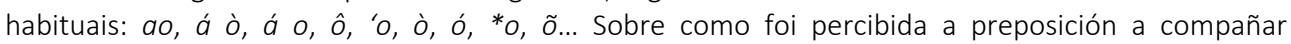
indebidamente $\mathrm{O} C D$ nos textos de finais do século XIX e inicios do século XX, véxase Sánchez Rei (2014b: 128-129).
} 


\section{XOSÉ MANUEL SÁNCHEZ REI}

cousa: é a acraración do atributo envolveito en todol-os verbos activos; é o que contesta â pregunta ¿qué cousa? referente ao verbo transtivo.

Exempros: Vou ouvir... ¿qué cousa? O predicador.

Onte vin... ¿qué cousa? O fillo de Xan.

Neste caso sería unha falla dicir ao predicador, ao fillo de Xan. Non se debe usar ô senon $o$ (artículo sômente). (ANT, 217: 7, 01.10.1925)

A centralidade desta cuestión levou máis autores a manifestaren o seu parecer, aínda que, ás veces, incorrendo precisamente no contrario que defendía L. C. Deste modo, José ReyGonzález, no seu prólogo “A vuela pluma. Sobre léxico gallego” á obra Fume de Pallas, saída do prelo en 1925, defendía con total clareza a presenza desa preposición, a argüír unha explicación fonética de máis que dubidosa verosimillanza e dando claras mostras dun dominio da lingua deficitario:

Concretándome a la observación práctica del punto en cuestión, y dejando a un lado otro género de consideraciones, yo entiendo que, si queremos expresar -por ejemplo- en gallego oralmente la frase castellana "vi al Rey", lo general es que se diga "vin ao Rei”, pronunciando ligeramente la $a$, de la cual nunca se prescinde por entero al emitir en nuestra lengua esos sonidos. (PTG, 217)

Asunto igualmente digno de interese é o relativo á documentación de tempos compostos con haber. O galego, sen cultivo literario durante séculos e perante uns tempos verbais compostos que en moitos casos se comportaban como verdadeiros sinónimos das equivalentes formas simples sen daren indicios de manteren oposicións semánticas con estas (Moscoso Mato, 2000: 219-220), deixou esquecidos tales tempos no camiño da época medieval á Idade Contemporánea. Moito embora aparecesen recollidos nalgunhas das gramáticas clásicas do galego (cf. Cuveiro Piñol, 1868; Saco Arce, 1868; Valladares, 1970; Lugrís Freire, 1931; etc.), foron, normalmente, entendidos como máis un exemplo do influxo do español. No interesante discurso de ingreso no Seminario de Estudos Galegos de Antonio Losada Diéguez "Encol da prosa galega", lido en 1924, mais publicado postumamente en 1930, o intelectual expuña, entre outros temas, como o galego podía ver acrecentadas as súa capacidades lexicais, mais tamén cargaba contra a presenza deses tempos compostos con haber como auxiliar e deixaba claro a necesidade de conceder ouvido atento á fala camponesa e de se preocupar pola gramática da lingua:

Todos temos visto como se enfouza a prosa galega empregando a eito o verbo haber en tempos compostos d-un xeito que non ademite a gramática galega [...]. De conseguinte ningunha cousa millor para avivecer a nosa feiticeira fala que o estudo da fala labrega, y-o estudo da gramática galega. (NÓS, 73: 2-5)

\subsection{Sintaxe e expresión literaria}

Outrosí, no Rexurdimento, comezaba a se notar que o galego, lingua fundalmentalmente rural naquela época, tiña de arrequentar as súas capacidades expresivas. Conforme avanzaba o cultivo literario dela, tamén se evidenciaba que o idioma tiña de se adaptar e modernizar de maneira a servir para calquera tipo de expresión literaria, o que se non vería parcialmente 
conseguido até á chegada das Irmandades da Fala e da Xeración Nós. Para iso, a recorrencia ao léxico ou até a "frases y modismos" ou "frases y giros" de linguas estrutural e xeograficamente próximas foi subliñada nalgúns escritos xa en finais do Rexurdimento. Así é o que se pode ler no seguinte fragmento de Andrés Martínez Salazar, pertencente a un artigo intitulado "En tela de juício" asinado como A. Marsal e publicado no ano 1888 en Galicia. Revista Regional; neste documento, para alén da cuestión ortográfica, da cal o autor era firme defensor dunha liña etimoloxista, tamén se falaba da grande axuda que poderían ser o español e o portugués para aprimoraren a expresión en lingua galega:

Por esto no me sorprende que el gallego adopte giros, frases y palabras portuguesas y castellanas, como me ha parecido ver en escritos de varios autores galicianos; que de no introducirlas para significar los adelantos en las ciencias, las artes, el comercio y la industria, valdría tanto como condenar el gallego á ser un monumento, una cosa que pasó, una lengua muerta, en fin. (Martínez Salazar, 1981: 46)

A resposta a ese texto, “A todos y a uno", aparece na mesma publicación apenas unhas semanas despois e é da autoría de José Barreiro Meiro, que, a pesar de se non decantar por unha ortografía etimoloxista e de preferir unha orientación foneticista, sinala a conveniencia dese proceder para aprimorar a sintaxe e o léxico do galego: "No he de negarle á V. la necesidad de introducir en nuestro dialecto palabras y giros portugueses y castellanos" (RLG, 308).

Noutras ocasións, os comentarios referidos aos trazos sintácticos nunha obra literaria parecen camiñar na dirección contraria ao se centraren non na permisividade, mais na crítica ao estilo. Deste modo, Manuel Ortiz Novo, no seu texto prologal "Pórtico. La aportación de Frade Giráldez al teatro regional. Antes de levantarse el telón” que preludia o traballo de Ricardo Frade Giráldez O Rey d'a Carballeira. Comedia dramática gallega en tres actos e catro coadros, saída do prelo en 1932, non dubidaba en atirar setas contra a sintaxe do texto: "La sintáxis que emplea peca un poco de audaz. Cuantos dominan y manejan con maestría el idioma gallego se quedarían un poco perplejos, debido esto a no dudarlo, a la anarquía que sigue imperando en el uso de la lengua vernácula" (Sanmartín Rei, 2002a: 167).

Tamén se indicou cal era o motivo desas "audacias" e desas influencias da sintaxe castelá. De aí que non faltasen textos en que se sinalou que a orixe da hibridación sintáctica entre galego e español é debida á falta de preocupación das galegas e dos galegos pola súa propia lingua. Nestes medios, non teñen perda as ideas, noutra ocasión, de Manuel García Blanco, recollidas do seu opúsculo Consideraciones..., xa citado máis arriba, onde sinalaba unhas atinadas observacións ao pór de relevo en termos sociolingüísticos as interferencias como máis unha proba da desquerenza das galegas e dos galegos polo idioma e a boa acollida xeral que recibían no idioma de chegada:

Del lamentable desafecto del pueblo gallego a su lengua constituye también prueba concluyente la corrupción que por doquiera la afea y aniquila. En vez de los propios y genuinos de la lengua indígena, tienen en toda la región uso corriente algunos sonidos exóticos, cientos de vocablos, crecido número de frases que, en atención a su procedencia, pueden llamarse castellanismos, a los cuales es debido que el gallego que en el día se habla (también el que se escribe: ni aun en los más castizos escritores galaicos dejan de manifestarse los estragos de la corrupción) tenga tanto de disonante y abigarrada jerga. Y 


\section{XOSÉ MANUEL SÁNCHEZ REI}

es de notar la gran aceptación de que goza el parecer de que tales barbarismos enriquecen y afinan nuestra lengua. (CDR, 10)

Mais a calidade dos textos dos protagonistas da reemerxencia literaria e cultural no século XIX e nos primordios da seguinte centuria non era, como é de supor, uniforme: ás tan diferentes capacidades artísticas de cada persoa acrecentábanse, outrosí, niveis tamén distintos no referente á correcta asimilación dos trazos gramaticais e lexicais daqueles escritos. Conscientes desa situación, as escritoras ou os escritores trataban de a xustificar a través do xogo retórico da captatio benevolentiae. En tales circunstancias, non faltaron referencias a contidos sintácticos, nova e vagamente referidos mediante "xiros" ou "frases", os cales podían centralizar subtilmente certo tipo de críticas amparándose no contexto lingüístico e literario da altura ou incentivar a comprensión do público lector. É o caso de Francisco Álvarez de Nóvoa, en cuxo texto prefacial "Dous parrafeos", que serve para abrir a porta á obra Pé das Burgas, dada a lume en 1896, puña o acento na súa procedencia foránea para desculpar os posíbeis erros lingüísticos desa colección de relatos:

Así, pois, os que non foron nados en Galicia, como eu, e corréron-a toda, e apreciaron esas difrenzas [dialectais da lingua], e deprenderon o idioma de viva voz [...], levamos a ventaxa de facer unha desapasionada escolleita n-os vocablos [...]. Por iso atoparedes, cicais, n-este libro algunha palabra que non sexa tan enxebre como deseárades, algún xiro típico virado, pro, si como andaluz que son, ben podía disculparme n-os defectos da fala gallega, prefiro que busquedes a razón $n-a$ belleza da frase, n-a lindeza do conxunto, n-a tersura, si así deixádesmo decir, da parrafeada. (PTG, 126)

Porén, é certo que unha das máis recorrentes liñas en que se fala da lingua galega e dos seus trazos gramaticais para a procura de modelos de lingua asentou na ponderación de linguaxes literarias dalgunhas personalidades da altura. En tales casos, o máis habitual é salientar con certa indefinición trazos xerais deses estilos e certas expresións ou xiros, o que, a pesar de non poder ser entendido estrita e univocamente pertencente ao dominio da sintaxe, si que está, desde logo, relacionado con esta. Así, un exemplo dito é o que se pode ler na recensión anónima "Bibliografía. Versos gallegos de Don José Pérez Ballesteros", a cal comenta a obra do famoso folclorista Versos en dialecto gallego; o tal comentario apareceu nas páxinas do Heraldo Gallego en 1878, no mesmo ano da publicación do poemario e, para alén de subliñar o emprego dunha linguaxe considerada correcta, tamén se significa polos "xiros" ou construcións sentidas como máis auténticas: "Las poesías del Sr. Pérez Ballesteros, distínguense especialmente por la corrección del lenguage, por sus jiros genuinamente gallegos" (RLG, 181).

Para alén dos trazos da lingua de Pérez Ballesteros, outros estilos literarios individuais concorreron na vangarda de modelos lingüísticos. Á marxe de Añón, Pondal ou Rosalía, comunmente louvados e postos como referencias pola súa transcendencia, diversos autores e autoras participaron nese concerto. Un deles foi Manuel Leiras Pulpeiro ${ }^{8}$, conforme se pode ver no "Prólogo" de Ramón Otero Pedrayo á edición das Poesías completas do mindoniense,

\footnotetext{
${ }^{8}$ Cf. Sanmartín Rei (2002a: 190), autora que sinala que dentro dun modelo lingüístico máis vinculado á oralidade tradicional os autores máis citados son "Noriega, quen no Catálogo de libros de Nós é publicitado como un modelo de lingua a aprender" e Leiras Pulpeiro, de quen se pon en valor o seu coñecemento lingüístico.
} 
aparecidas en 1930; nese texto, en que se pondera a galeguidade dos poemas do autor mindoniense e a del propio, sinálase como a súa lingua constitúe unha "canteira" de autoctonía lingüística que resultaba inusual en autoras e autores das urbes polos "xiros" e expresións:

Todol-os versos qu'ides lêr testemoñan o fondo sentimento galego e galeguista de Leiras Pulpeiro. Coñecía o noso pobo coma poucos o coñeceron, falaba a linguaxe eispresiva [...]. Considerade os poemas "Un Galo", "Xudío" de doada feitura, ademirabre senso das cousas pequenas, sin importanza aparente entr'as que decorre o vivir labrego, n'outros puramente ouxetivos que teñen que ficar sempre como canteira de verbas, d'eispresiós, de xiros, de pensamentos descoñecidos dos escritores da cidade. (Sanmartín Rei, 2002a: 190-191).

Máis un dos autores cuxa expresión foi obxecto de comentario corresponde a Ramón Cabanillas, conforme se le no prólogo de Aquilino Iglesia Alvariño a unha edición da poesía do poeta cambadés; naquelas palabras indicábase que o autor tiña de se decantar por unha liña gramatical, incluída a sintáctica, que el propio debía seleccionar:

Cabanillas, que leva na súa fala a voz desta Galicia, tén que facer algo máis que escoller nos tesouros dunha lengua de cultura universal, rica e fixada por unha longa tradición literaria, a espresión máis xusta das súas afecciós en virtú dos seus sentimentos e preferencias literarias. Tén que escoller, sí, pro seguindo unha liña fonética e morfolóxica, lesical e sintática, que el mismo tén que ir descubrindo á partir dunha lengua común apartada da súa tradición literaria pola presencia e presión doutra lengua irmá. (Sanmartín Rei, 2002a: 168)

E sen deixar de pór en valor estilos literarios persoais, como neste caso o de Castelao, Manuel Lugris Freire sinalaba, nunha conferencia recensionada e publicada fragmentariamente no boletin A Nosa Terra en 1926, algunhas características do galego, a incluír tamén algún comentario de carácter sintáctico: (i) a antigüidade da lingua galega; (ii) o feito de diacronicamente variar pouco nas súas construcións, que continuaban a ser, segundo o autor, as mesmas que as da época medieval; e (iii) os usos inadecuados que se facían na altura do infinitivo persoal, unha vez que foi identificado como un dos trazos característicos do sistema lingüístico galego-portugués:

a fala galega está feita dende hai moitos séculos: que, contradicindo certos principios filolóxicos, variou moi pouco no seu léxico, e menos ainda no réxime e construción, que sigue sendo o mesmo dos tempos trovadorescos e do século en que foi escrita a Crónica Troyana [...]. E non falemos do mal uso que se fai do infinito persoal dos nosos verbos, en col dos que xa teño dito todo o que ê mester na miña Gramática do idioma galego [...].

Castelao, o querido artista, escribe n-un galego que mesmo sabe a groria pol-o escollido e ben apricado das suas verbas e pol-a enxebre e indiscutibre construcción. (ANT, 224: 3-4, 01.05.1926)

Por súa vez, o descubrimento dos textos medievais en finais do século XIX tivo como consecuencia alongar a historia da literatura galega e o horizonte do idioma, e favorecer que a lingua medieval puidese servir como un poderoso elemento socioloxicamente dignificador. Mais tamén implicou que a literatura do Medievo se erixise en referencia modelar para a mellora do léxico e da gramática e que este recurso fose, consecuentemente, salientado 
nalgunhas publicacións 9 . Por iso, non é de estrañar que as autoras e os autores da época botasen man dos hoxe chamados arcaísmos para recuperaren o vocabulario erosionado polo español ou para se afastaren de fasquías consideradas propias desta lingua e que tivesen nos textos antigos unha poderosa axuda para melloraren a expresión literaria. Así as cousas, facendo case equivaler gramática e sintaxe na liña do sinalado máis arriba, Manuel R. Rodríguez, nos seus "Apuntes gramaticales y vocabulario" á edición da Crónica Troyana, dada a lume por Andrés Martínez Salazar en $1900^{10}$, deixaba constancia de diversas situacións que se daban con frecuencia entre quen escribía en galego; a seu ver, era necesario limpar a lingua de vicios da gramática e do léxico, ao paso que denunciaba que había xente que presumía deses pouco recomendábeis usos:

Es, sin embargo, forzoso confesar que es una lengua inculta el idioma gallego, cuyos vicios gramaticales es necesario extirpar, reformulando su vocabulario y reduciendo á reglas precisas su gramática, á fin de que sirva de guía a muchos de nuestros escritores contemporáneos, que pretenden hacer pasar tales defectos por elegancias y bellezas gramaticales. (Rodríguez, 1900: 5)

A insistir nesta idea, expuña o modelares que poderían ser os textos dos clásicos do Rexurdimento limpos dos elementos gramaticais alleos, xa que, a seu ver, aquelas composicións "revelan hasta qué punto podía elevarse la literatura gallega, extirpando de ella la multitud de impropiedades, que pululan en su lenguaje y que han quedado incólumes por ser consideradas bellezas gramaticales" (1900: 5). No mesmo estudo, significa a Crónica troiana como fonte en que se inspirar para mellorar a calidade lingüística, pois é a "fuente más clásica á donde deben acudir nuestros escritores para la redacción gramatical de sus composiciones literarias" (1900: 5-6). Relativamente a estas cuestións, non ten perda o excerto que citamos máis abaixo, de onde poden tirarse interesantes ideas: (i) a autenticidade das combinacións das partículas prepositivas que dan orixe ás diferentes tipoloxías de frases preposicionais; (ii) o uso certo das formas clíticas do pronome persoal; (iii) a (probábel) referencia á detección de casos de interpolacións pronominais ("trasposiciones"); e (iv) a existencia de xiros e expresións xenuínas que identifican a lingua galega. Na súa opinión, por tanto, na Crónica troiana

se encuentran esa genuinas contracciones á que da origen la combinación especial de las preposiciones de procedencia latina con los artículos $o$, $a$, os, as, traídos del griego para formar la declinación gótico-gallega; allí se halla el verdadero empleo que debe hacerse de los pronombres personales $m e$, te, che, se, lle, etc., y raras y caprichosas trasposiciones á que da lugar esta partícula gramatical, cuyos juegos de palabras tanto contribuyen a caraterizar la lengua; abundan allí, finalmente, esos giros peculiares y castizos que tanto distinguen el

\footnotetext{
${ }^{9}$ Losada Diéguez, por exemplo, no seu discurso "Encol da prosa galega" xa comentado máis arriba, non hesitaba en animar ao estudo da lingua antiga para facer máis lucido o galego literario: "I-os que remexen na historia de Galiza poden dar mais grande amparo ô rexurdimento da língoa, traballando n-o vocabulario da prosa galega da Edade Medea fonte e deloiro ô mesmo tempo da nosa literatura" (NÓS 73: 5).

${ }^{10}$ Unha parte deste estudo de Manuel R. Rodríguez sería traducida e publicada vinte anos despois so o significativo título de "Unificación e melloramento do idioma gallego" no decenario das Irmandades da Fala (ANT, 141: 1, 31.05.1921).
} 
idioma de los moradores de nuestras comarcas gallegas, y esas hermosa frases da terriña. (Rodríguez, 1900: 6)

Finalmente, outros escritos resultan singulares polas relacións que estabelecen entre as construcións sintácticas e as condicións rítmicas dos textos poéticos e prosaicos. En tales circunstancias é que se acha o prólogo "Ao leitor", que preludia a obra de Aurelio Ribalta Pose Altariño de amore. Estoria romántica, dada a lume en 1935. Nel, o autor emite uns xuízos de valor sobre a relación entre o ritmo da poesía, o da prosa e a existencia de determinadas construcións, identificadas por el como locución, frase e período, o que é digno de nota pola nomenclatura empregada, parcialmente recorrente no discurso gramatical contemporáneo; con independencia do que el puidese entender baixo esas denominacións, non deixan de carecer de interese as súas impresións:

O qe ai, e qe na poesía, êsto, na lênguaxe bersificada, as ideias simpres son coma na prosa, espresadas pola locuzêón; pro a xuntanza de locuzêós qe na prosa fai a frase, na poesía fai o berso; e o período da prosa faise estrofa na poesía.

A correspndenza eibos êsta:

Prosa: locuzêón, frase, período.

Berso: locuzêón, berso, estrofa.

A difrenza antre a prosa e ma lo berso, está na maor comprexidá dos ritmos.

O ritmo da lênguaxe é: O mobemento ordenado das espresiós suzesibas.

Este mobemento e mais êsta ordenanza, refírese às ideias (fondo da lênguaxe) e mais a os sons (fonemas, sílabas, pes rítmecos, forma de lênguaxe).

$\mathrm{Na}$ prosa, os ritmos da locuzêón, da frase e do período, se non suxetan a ningún mobemento predeterminado e con regras própeas.

No berso, os ritmos da locuzêón, do berso e do período, suxétanse a ouserbaren unha orde de ritmos adoutada d'antemán polo poeta. (PTG, 281)

\subsection{Sintaxe e realidade da lingua}

A mestura sintáctica ou a falta de estudos sobre gramática enformaban as faces dunha figura poliédrica en que tamén se anunciaba a ausencia de modelos lingüísticos, parcialmente procurados en certos vultos da literatura. Sobre este particular, saberen as autoras e os autores onde se podía achar unha variedade enxebre foi unha cuestión que inspirou algunhas reflexións da época. O polimorfismo que caracteriza a produción literaria na altura e a diferente percepción do que debía pasar da lingua oral á linguaxe literaria explican con facilidade o aparecemento das diversas opinións que levantou esa situación. Para algunha xente, a referencia lingüística modelar tiña de ser a constituída pola oralidade tradicional e popular, segundo a primeira das liñas sintetizadas por Sanmartín Rei a que xa fixemos referencia máis arriba; tal é o caso do presbítero Manuel Vidal Rodríguez, o cal, no "Prefacio" á súa obra Deixe que xa... Cuentos y novelas cortas de asunto gallego, publicada no ano 1931, non tiña dúbidas en se dirixir ao galego popular e ás súas construcións "peculiares" para esa procura:

Huyendo, como de cosa vitanda, de ese Gallego artificioso, insulso y aportuguesado, que modernamente usan algunos, me he inspirado en el lenguaje del pueblo, que suministra la materia prima idiomática, con los primores de sus tropos, modismos y giros peculiares, $\mathrm{y}$ es a la vez el depositario de las tradiciones y del alma galaica. (PTG, 154-155) 
Esta case bucólica visión da lingua oral contrasta fortemente co punto de vista de Fuco G. Gómez. Desta maneira, no texto "Judizo crítico da aitual grafía galega" pertencente ao seu proxecto de gramática Grafía galega, sinala desde Cuba que nin todo o que lingüisticamente se detecta no pobo debe ser elevado á escrita literaria, idea tamén partillada neste lado do Átlántico por algunhas persoas na altura e mesmo na nosa época ${ }^{11}$. Para soster este punto de vista, acode ás prescricións da máxíma autoridade do idioma español relativamente a expresións, fraseoloxías e estruturas sintácticas de uso habitual nesta lingua, embora sentidas como incorrectas por esa institución. A comparación que estabelece co galego asenta na circunstancia de que, se esas construcións no español son censurábeis, tamén no caso do noso idioma habería que marcar unha especie de barreira para impedir que construcións de dubidosa validade gramatical ou sentidas como incorrectas soborden a lingua oral e pasen indebidamente á linguaxe literaria, por moita que fose a súa utilización:

Xi correito é empregar tudol-os termos e eispresiós do noso pobo tal coma il soe pornunzial-os, e xi lógico é qui usémol-o sistema de isquirtura qui empregaron aqués qui soio se ativeron ao xeito de falar da genti inculta, eu non sei per quí a Real Academia Española chata de barbarismos os isquirbir bajo este punto de vista, per desde este punto de vista; el mes que rige, en vez de el mes actual [...] las dí los jugutes a las niñas ou los dí la mano a los dos, en vez de les dí los juguetes a las niñas ou les dí la mano a los dos $[\ldots]^{12}$.

Taes barbarismos e solecismos cométen-os con moitísima frecoenza incrusive moitos profesionaes e prodistas d'ofizio ao eispresar-se no hespañol; contodo a Academia non os tolera, nen os recoñesze coma linguaxe correito, coma fain os nosos gramáticos con respeito aos múltipres disparates qui son tan comúns no galego.

$\mathrm{Xi}$ milleiros d'hespañoes qui se instruíron en escolas españoas cometen de cote fallas gramaticaes sinaladas per nós e outras moitas, coma iso de dizir: aún todavía, mas sin embargo, etc., e escadasí isto a Academia non as tên noutro senso, cóma nós têmos de faguer leis gramaticaes os incontabres barbarismos e solecismos que comete un pobo qui leva mais de cinque séculos baixo un jugo estranxeiro, sen têr contado endejamais cunha verdadeira escola da sua lingua? (Gómez, 1927: 13-15)

\section{Conclusións}

En síntese, podemos concluír que a sintaxe conseguiu inspirar varios textos e pronunciamentos desde finais do século XIX até aos primeiros decenios da seguinte centuria. Nuns momentos en que socioliterariamente se potencia todo aquilo que se torna máis

\footnotetext{
${ }^{11}$ En 1916, dando continuidade a unhas aulas de lingua galega que os "amigos da fala" impartían na Real Academia Galega, apareceu nas páxinas d'A Nosa Terra unha sección intitulada "Escola do idioma galego", en que tamén se pode ler o seguinte: "o noso idioma está moi lixado polo uso dos nosos labregos e hai que ter coidado na escolleita que entre d'eles se faga. Porque eles digan frábica, auja, subiabámos, colliabámos, juevos e outras cousas do mesmo xeito non podemos nin debemos imitalos. Con un pouco de tento, d'estudio e amor pol-a nosa lingua, ben podemos escoller, no medio do aluvión que a inxuria dos tempos puxo no noso camiño, o puro e brilante ouro da nosa nobre e doce fala" (ANT, 3: 3, 05.12.1916). A propósito de textos da actualidade que desenvolven estas temáticas, cf. Freixeiro Mato (2014) ou Sánchez Rei (2014b).

12 Nesta ocasión, mantemos o uso de negras e itálicas segundo aparece no texto orixinario. Suprimimos tamén a longa lista de exemplos de frases feitos e de construcións sintácticas sinaladas como erros gramaticais pola RAG.
} 
diferencial a respecto do español, foi a reflexión sintáctica un saber lingüístico en que se depositaron non poucos albos como garantía dunha lingua autóctone. Nestes medios, aspectos cal a hibridación co español, a identificación da sintaxe coa cerna da lingua, a procura de modelos lingüísticos etc. aparecen desenvolvidos en diversas publicacións e textos prefaciais desa época, a mostraren así puntos de confluencia co que se pensaba para a sintaxe nas gramáticas daqueles tempos.

Conforme se torna obvio, o valor de cada un deses comentarios, os cales podemos agrupar baixo a epígrafe de sociosintaxe, é tremendamente irregular, tanto polo diferente grao de agudeza e rigorosidade das observacións recollidas como pola desigual preparación gramatical e filolóxica das persoas que os redixiron. A isto, igualmente, convén ligarmos o facto de o contexto en que van saíndo do prelo tamén non ser idéntico tendo en conta os avanzos producidos no coñecemento da lingua desde meados do século XIX até ao ano 1936. Como quer que sexa, cada un ao seu modo, evidenciaron a preocupación polo coidado de que debía ser obxecto a sintaxe na procura dun modelo de lingua digno nun contexto de contacto lingüístico desfavorábel para o galego. E algunhas desas impresións son facilmente extrapolábeis á actualidade, en que se perpetúa unha profunda erosión das estruturas sintácticas da lingua, e unha perda notabilísima de - como costumaban salientar na altura - xiros, frases e construcións idiosincráticas do idioma tanto na lingua oral como na escrita, substituídas ou influídas polas correspondentes do español. Por iso, os tres principios que sinalamos como garantía dunha praxe lingüística de calidade para a nosa época (selección, supresión/secundarización e valorización) achan xa na época do Rexurdimento e das Irmandades da Fala equivalencias, se non exactas, si cando menos confluentes, nuns casos máis e noutros menos, con estes tales criterios.

A calidade no uso do idioma, en definitivo, atravesa todas as disciplinas e saberes de natureza lingüística, desde os máis evidentemente preponderantes na reflexión gramatical até aos máis laterais neste ámbito. E de entre todos eles, pensamos que é a sintaxe un dos elementos que mellor serve para caracterizar un uso exemplarizante da lingua, recollendo así, en certa medida, esas reivindicacións daquelas persoas que viron nas construcións e nas estruturas sintácticas unha compoñente esencial da autenticidade idiomática.

\section{BIBLIOGRAFIA:}

ANT = (s. a.). A Nosa Terra. Anos 1916-1936. (ed. facsimilada). A Coruña: Xuntanza.

ANT' = (s. a.). A Nosa Terra. Anos 1907-1908 (ed. facsimilada). A Coruña: Edman \& J. L. Manrique.

CDR = GARCÍA BLANCO, Manuel (1912). Consideraciones sobre la decadencia y rehabilitación de la lengua gallega. Lugo: El Norte de Galicia.

CG = POCIÑA, Andrés \& MARCO, Aurora (Eds.). (1992). Rosalía de Castro, Cantares gallegos. Santiago de Compostela: Sotelo Blanco.

CIDRÁS ESCÁNEO, Francisco Antonio (2005). A sintaxe na gramática: problemas de descrición e problemas de prescrición. In Rosario ÁLVAREZ \& Henrique MONTEAGUDO (eds.), Norma lingüística e variación. Unha perspectiva desde o idioma galego (pp. 334-357). Santiago de Compostela: Instituto da Lingua Galega \& Consello da Cultura Galega.

CUVEIRO PIÑOL, Juan (1868). El habla gallega. Observaciones y datos sobre su origen $y$ vicisitudes. Pontevedra: Imprenta de José A. Antúnez y Cía.

FERNÁNDEZ SALGADO, Benigno \& MONTEAGUDO ROMERO, Henrique (1995). Do galego literario ó galego común. O proceso de estandarización na época contemporánea. In 
Benigno FERNÁNDEZ SALGADO \& Henrique MONTEAGUDO ROMERO (eds.), Estudios de sociolingüistica galega. Sobre a norma do galego culto (pp. 99-176). Vigo: Galaxia.

FREIXEIRO MATO, Xosé Ramón (2006). Gramática da lingua galega. Vol. I. Fonética e Fonoloxía (2a ed.). Vigo: A Nosa Terra.

FREIXEIRO MATO, Xosé Ramón (2009). Lingua de calidade. Vigo: Xerais.

FREIXEIRO MATO, Xosé Ramón (2014). Lingua oral, calidade da lingua e futuro do galego. In Xosé Manuel SÁNCHEZ REI (ed.), Modelos de lingua e compromiso (pp. 13-84). A Coruña: Baía Edicións.

FREIXEIRO MATO, Xosé Ramon \& SÁNCHEZ REI, Xosé Manuel \& SANMARTÍN REI, Goretti (2005). A lingua literaria galega no século XIX. A Coruña: UDC.

GARCÍA-MIGUEL, José Manuel (2000). Linguas do mundo e tipoloxía lingüística. In Fernando RAMALLO et al. (eds.), Manual de Ciencias da Linguaxe (pp. 173-220). Vigo: Xerais.

GARCÍA-MIGUEL, José Manuel \& CABEZA, Carmen (2000). Sintaxe. In Fernando RAMALLO et al. (eds.), Manual de Ciencias da Linguaxe (pp. 543-583). Vigo: Xerais.

GÓMEZ, Fuco G. (1927). Grafía galega. Habana: Emplenta e Papeleiría de Rambla, Bouza y Ca.

GUGENBERGER, Eva (2013). O cambio de paradigma nos estudos sobre contacto lingüístico: pode ser útil o concepto de hibrididade para a lingüística e política de linguas en España?. In Eva GUGENBERGER et al. (eds.), Contacto de linguas, hibridade, cambio: contextos, procesos e consecuencias (pp. 17-47). Santiago de Compostela: Consello da Cultura Galega.

GUGENBERGER, Eva et al. (Eds.). (2013). Contacto de linguas, hibridade, cambio: contextos, procesos e consecuencias. Santiago de Compostela: Consello da Cultura Galega.

HUDSON, Richard A. (1981). La Sociolingüística. Barcelona: Anagrama.

IGLESIAS ÁLVAREZ, Ana (2013). "Eu falo castrapo" - Actitudes dos adolescentes ante a mestura de linguas en Galicia (estudio piloto). In Eva GUGENBERGER et al. (eds.), Contacto de linguas, hibridade, cambio: contextos, procesos e consecuencias (pp. 169-189). Santiago de Compostela: Consello da Cultura Galega.

LUGRÍS FREIRE, Manuel (1931). Gramática do idioma galego (2a ed.). A Cruña: Imprenta Moret.

MARTÍNEZ SALAZAR, Andrés (1981). Algunos temas gallegos. Vol. II. A Coruña: Gráficas do Castro \& Moret.

MARTINS, Nilce Sant'Anna (2000). Introdução à Estilística. A Expressividade na Lingua Portuguesa (3 ${ }^{\text {a }}$ ed.). São Paulo: T. A. Queiroz, Editor.

MCB = LÓPEZ VIÑAS, Xoán (Ed.). (2006). Uxío Carré Aldao, Memoria crítico-bibliográfica sobre el Teatro Regional Gallego. A Coruña: Departamento de Galego-Portugués, Francés e Lingüística.

MOSCOSO MATO, Eduardo (2000). Os tempos compostos no galego medieval. Anexo 46 de Verba. Santiago de Compostela: USC.

NEVES, Maria Helena de Moura (2001). A Gramática. História, Teoria e Análise, Ensino. São Paulo: Universidade Estadual.

NÓS = (1987). Nós. Boletin Mensual da Cultura Galega (ed. facsimlada). A Coruña: Xuntanza.

PTG = SANMARTÍN REI, Goretti (Ed.). (2002b). Os (pre)textos galegos (1863-1936). Estudio e escolma dos prólogos. Santiago de Compostela: Sotelo Blanco.

RIEMSDIJK, Henk van \& WILLIAMS, Edwin (1990). Introducción a la teoría gramatical. Madrid: Cátedra. 
RLG = HERMIDA, Carme (Ed.). (1992). A reivindicación da lingua galega no Rexurdimento (1840-19891). Escolma de textos. Santiago de Compostela: Consello da Cultura Galega.

RODRÍGUEZ, Manuel R. (1900). Apuntes gramaticales sobre el romance gallego de la Crónica Troyana. In Andrés MARTINEZ SALAZAR (ed.), Crónica Troyana. Códice gallego del siglo XIV, apuntes gramaticales y vocabulario de Manuel R. Rodriguez (pp. 1-87). A Coruña: Imprenta de la Casa de Misericordia.

SACO ARCE, Juan Antonio (1868). Gramática gallega. Lugo: Imprenta de Soto Freire.

SÁNCHEZ REI, Xosé Manuel (2005). Trazos xerais da tradición gramatical galega. Revista Galega de Filoloxía, 6, 93-121.

SÁNCHEZ REI, Xosé Manuel (Ed.). (2014a). Modelos de lingua e compromiso. A Coruña: Baía Edicións.

SÁNCHEZ REI, Xosé Manuel (2014b). A preocupación por unha lingua de calidade. Aproximación histórica ao caso galego. In Xosé Manuel SÁNCHEZ REI (ed.), Modelos de lingua e compromiso (pp. 85-149). A Coruña: Baía Edicións.

SÁNCHEZ REI, Xosé Manuel (2019). As motivacións da sintaxe na docencia. In Maria Aldina MARQUES \& Xosé Manuel SÁNCHEZ REI (eds.), Estudos atuais de linguística galegoportuguesa (pp. 119-149). Santiago de Compostela: Laiovento.

SANMARTÍN REI, Goretti (2002a). Lendo nas marxes. Lingua e compromiso nos paratextos (1863-1936). A Coruña: Espiral Maior.

SANMARTÍN REI, Goretti (2008). Nos camiños do entusiasmo. Vigo: Xerais.

SANMARTÍN REI, Goretti (Ed.). (2012). Consideracións sobre a decadencia da lingua galega. Homenaxe a Manuel García Blanco. Monografía 7 da Revista Galega de Filoloxía. A Coruña: Área de Filoloxía Galega e Portuguesa da UDC.

VALLADARES, Marcial (1970). Elementos de gramática gallega. Vigo: Galaxia.

VOLÓSHINOV, Valentin Nikoláievich (2014). El Marxismo y la filosofía del lenguaje. Buenos Aires: Godot. 
